\title{
AUGE Y DECADENCIA DEL SISTEMA MISIONAL FRANCISCANO EN FLORIDA DURANTE EL PRIMER PERIODO ESPAÑOL (1565-1763)
}

La provincia de Florida había resultado, desde los inicios de su colonización y asentamiento, dura y difícil para vivir y trabajar en ella; los constantes ataques de potencias extranjeras, a que se vio sometida la población, impidieron una explotación sistemática de la tierra y, la lejanía y problemas de comunicación con otros territorios partenecientes a la Corona española, unida a la dilación en la solución de los diferentes asuntos que se plantearon, conllevó en la mayoría de los casos una compleja y lenta administración.

\section{I) Antecedentes EVANGELizadores}

Tras los intentos frustrados de dominicos y jesuitas desde mediados del siglo XVI para conseguir la evangelización del territorio, fueron los franciscanos quienes secundaron con éxito la ingente labor misional, ocupando su trabajo apostólico prácticamente el llamado Primer Período Español en esta provincia (15651763). La primera fecha marca la fundación de la ciudad de San Agustín, la capital y el núcleo receptor de las continuas expediciones misioneras que se comenzaron a enviar desde la península; la segunda, el año del traspaso de Florida bajo el dominio inglés.

La presencia franciscana se inició a partir de 1573 , ya que el 23 de febrero de ese mismo año, fue expedida en Madrid una real cédula ordenando en ella al adelantado Menéndez de Avilés que continuase la labor de colonización emprendida en tierras flori- 
danas y que le acompañasen 12 frailes de la orden de San Francisco. ${ }^{\text {: }}$

Posteriormente fueron llegando a intervalos regulares, nuevos contingentes de misioneros franciscanos, instalándose en la costa oriental de las provincias septentrionales y limitando en principio su acción al territorio comprendido entre San Agustín y Santa Elena (actual Port Royal Sound).

Pronto iniciaron los religiosos la organización misional del territorio denominado en sus inicios Provincia Franciscana de Santa Cruz. En 1588 se convirtió en la denominada Custodia de Santa Elena, ${ }^{2}$ cuya autoridad máxima era el custodio o comisario. En 1609 se le agregaron los conventos de la isla de Cuba y en 1612 alcanzó el rango de Provincia Regular de Santa Elena, comprendiendo, además de esta isla, parte de los estados de Georgia y Carolina del Sur, incorporándose también las regiones de Potano y Timucua y estableciéndose contacto con la gran nación Apalache, cuya evangelización sistemática no pudo sin embargo emprenderse hasta $1633 .^{3}$

\section{a) Inicio de las predicaciones}

Con respecto a las misiones, son difíciles de seguir estos comienzos evangelizadores, al no existir ninguna crónica y contar tan sólo con algunos documentos de información fragmentaria, y a veces, incluso contradictoria.

En una de las primeras expediciones (1587) fue fray Alonso de Escobedo, gracias al cual y a su obra «La Florida», conocemos

1 Ruidíaz y Caravia, E.: La Florida. Su conquista y colonización por Pedro Menéndez de Avilés. Tomo II. Madrid, 1894, págs. 295-298.

2 Oré, Luis Jerónimo de: Relación histórica de la Florida (S. XVII). Edición, prólogo y notas del P. Atanasio López O.F.M. Madrid, 1931, tomo I, páginas $49-51$.

3 Omaechevarría, Ignacio: Sangre vizcaina en los pantanos de la Florida. (F'ray Francisco de Beráscola, 1564-1597). Vitoria, 1948, pág. 47. Gannon, Michael V.: The Cross in the Sand. The Early Catholic Church in Florida (1513-1870), Gainesville, 1983, pág. 50. Oré, Luis Jerónimo de: Relación histórica..., tomo I, págs. 112-119. 
en parte estos primeros momentos de intentos de adoctrinar el territorio. Este religioso perteneció a la expedición que llevó por comisario a fray Alonso de Reinoso. Provenía de la Provincia Regular de Andalucía y nada más arribar a tierras floridanas, fue enviado al pueblo de Nombre de Dios, cercano a San Agustín.

$\mathrm{Su}$ obra, nunca publicada en su totalidad y conservada en la Biblioteca Nacional de Madrid, es un extenso poema de 449 folios, dividido en tres partes, conteniendo una completa historia, con amplias noticias del país y de los acontecimientos que allí sucedieron en los años que ejerció su labor evangelizadora. Está calificada como de lo mejor que se escribió referente a esta provincia en el siglo XVI, supliendo en gran parte la falta de muchos hechos no conocidos por otro conducto, y constituye en sí un documento histórico de gran importancia, dada su conformidad y exactitud de las relaciones, que otros autores no aportan. ${ }^{4}$ Las impresiones sobre el avance de las misiones en estos años eran excelentes, puesto que los religiosos, aparte de la labor realizada, contaron el] muchos casos con el apoyo de los gobernadores, como fue cl caso de Martínez de Avendaño (1594-1595), hombre activo, intachable y muy celoso de la difusión de la fe católica entre los naturales. Según se afirmaba, rigió la provincia con tal acierto y prestigio que vinieron a instruirse y bautizarse hasta algunos indígenas de tierra adentro, situados fuera de la jurisdicción española, ya de las clases principales, como del común, acompañados de sus mujeres e hijos. En 1595, el número de indios cristianizados era de $1.500,{ }^{5}$ lo que supuso la petición de nuevos religiosos para ir ampliando el campo de acción misional. ${ }^{6}$ Pronto se registró un núcleo denso de indígenas cristianizados en la isla de San Pedro

4 Lejarza, Fidel de: Rasgos autobiográficos del P. Escobedo en su poema «La Florida». «Revista de Indias», I, núm. 2, Madrid, 1940, págs. 35 y 36 . Geiger O.F.M., Maynard: Biographical dictionary of the franciscans in Spanish Florida and Cuba. Paterson N. J., 1940, pág. 48. Gannon, Michael V.: The Cross..., páginas 38 y 39 .

5 Campen, J. T'. Van: St. Augustine. Florida Colonial Capital, 1959, pág. 23.

6 Archivo General de Indias (en adelante A.G.I.), Santo Domingo, 235. San Agustín, 23 de enero de 1596. El custodio fray Francisco Marrón, mostraba su agradecimiento por los continuos envíos de misioneros que se estaban realizando e informaba que habían sido repartidos por las provincias y pueblos de Timucua, Guale y Aguadulce. 
(actualmente Cumberland Island), cuyo cacique don Juan, prestó a los religiosos una valiosísima ayuda para convertir y «rcducir a los demás indios», llegando a proporcionar víveres y ayuda a otros pueblos en tiempo de necesidad. ${ }^{7}$

\section{b) Expedición a la Tama}

Aunque los misioneros circunscribieron su acción a las regiones más cercanas a San Agustín, como hemos comentado, se comenzaron a efectuar por estos años exploraciones, acompañadas casi siempre de religiosos, a regiones más apartadas, como es el caso de la efectuada en 1597 a la Tama, a unas 50 leguas tierra adentro. Generalmente y aunque a veces la excusa presentada era la evangelización, el fin primordial de éstas, como ocurrió en muchos otros territorios del Nuevo Mundo, fue el económico, a la búsqueda de posibles yacimientos mineros.

Para acompañar a los soldados fueron designados los padres fray Pedro Fernández de Chozas y fray Francisco de Beráscola, ${ }^{8}$ llevando como intérprete al soldado Gaspar de Salas «por entender la lengua de la provincia de Guale y de San Pedro». " Habiendo salido de San Agustín en la primavera de ese año, no hallaron buena tierra hasta llegar a la dicha Tama, donde los religiosos comenzaron a adoctrinar a los naturales. En las regiones de Cuaque, Talufa y Usatipa hicieron importantes descubrimientos sobre las riquezas naturales, pero al tratar de penetrar aún más hacia el interior, el cacique del pueblo de Ocute les aconsejó el regreso ya que consideró que se exponían a perder la vida. El viaje de vuelta

7 El padre fray Baltasar López, que llevaba ya unos 10 años en la Florida, había educado y bautizado a este cacique o señor principal de la isla, predicándoles a todos sus vasallos en la lengua timucua, propia de aquel paraje. Cartas de Fray Francisco Pareja y Fray Baltasar López. «Archivo Ibero Americano», tomo I, Madricl, 1914, págs. 362-364.

8 A.G.I., Contratación, 5.538. Ambos llegaron a este territorio con la expedición que el 14 de julio de 1595 salió de Sanlúcar de Barrameda, llevando comb comisario a fray Juan de Silva.

9 Arnade, Charles W.: Florida on trial (1593-1602). Florida, 1959, pág. 46. Geiger O.F.M., Maynard: The franciscan conquest of Florida (1573-1618). Washington, D.C., 1937, pág. 82. 
lo realizaron pasando Yufera y Cascangu, pueblos de indios aliados. Los resultados obtenidos fucron escasos, pero tuvieron la gran ventaja de ir aportando las primeras noticias y datos sobre estas nuevas regiones y sus habitantes. ${ }^{10}$

También por estas mismas fechas, comenzaron a surgir problemas entre el gobernador, los religiosos y los indígenas que crearon graves tensiones, llegándose incluso, por parte de los naturales, a verdaderos enfrentamientos contra los españoles, situaciones que comentaremos posteriormente, pero que nos vienen a confirmar el grado de tensión existente al convivir sociedades y grupos tan dispares, difíciles de compaginar; tendentes por parte de la población civil española a lograr una rápida obediencia y sumisión de los naturales y por parte de los misioneros, alterando su modo de vida, circunstancia frente a la que los naturales se mostraron en franca rebeldía. En muchos casos, la táctica indígena para no acatar las obligaciones impuestas por los religiosos, fue marcharse de las doctrinas e internarse tierra adentro. ${ }^{11}$

\section{c) La revuelta de 1597 en Tolomato}

En este ambiente surgió la rebelión, consecuencia de todos los factores anteriormente mencionados y que merecen la pena ser comentados para intentar esclarecer las circunstancias de la misma.

El gobernador Gonzalo Méndez de Canzo, al contrario que su antecesor Martínez de Avendaño, fue tachado de proceder contra los indígenas con crueldad, con precipitación, con desaciertos frecuentes que pronto fueron denunciados incluso por los propios misioneros al ser de «...gran escándalo para los recién convertidos a la fe y es grande obstáculo e impedimento para otros que tenían el santo propósito de convertirse...». ${ }^{12}$

10 Geiger O.F.M., Maynard: The franciscan conquest..., pág. 8z.

11 Documentos históricos de la Florida y la Luisiana (S. XVI-XVIII). Madrid, 1912, págs. 143-145. Oré, Luis Jerónimo de: Relación histórica..., tomo I, pág. 93.

12 A.G.I., Santo Domingo, 235. San Agustín, 8 de marzo de 1599. De fray Francisco Pareja al Rey. 
Los religiosos desde comienzos de la evangelización, trataron de prohibir costumbres sociales de los indígenas incompatibles con el catolicismo, como la poligamia y el concubinato y ello fue la causa principal de esta sublevación. Por el Confesionario de tray Francisco Pareja, se puede deducir hasta qué grado trataron los franciscanos de modificar las costumbres sociales, ceremoniales y sexuales de los indígenas floridanos. En él se incluyeron preguntas sugestivas para el uso del fraile durante las confesiones, que abarcaban los ritos tradicionales para la caza, la agricultura, costumbres médicas, la magia y actividades políticas. El Confesionario también nos revela que las costumbres tradicionales entre hombres y mujeres y su conducta sexual se consideraban pecaminosas para los frailes, ${ }^{13}$ según se desprendió además de las declaraciones de los propios naturales y que posteriormente se realizaron, en un proceso llevado a cabo para el esclarecimiento de los hechos. ${ }^{14}$ Los fines perseguidos por los indígenas en este levantamiento fueron: matar a los misioneros e indios cristianos, preparar la guerra y provocar una insurrección general contra todos los españoles. ${ }^{15}$

Los franciscanos que murieron a causa de esta revuelta fueron: fray Pedro de Corpa, fray Miguel de Añón, fray Antonio, fray Blas Rodríguez y fray Francisco de Beráscola. ${ }^{16}$ Fray Francisco de Avila fue hecho prisionero y sometido a crueles torturas, siendo al fin rescatado por una patrulla española al ser canjeado por un cacique cautivo. Años más tarde fue a La Habana, donde escribió un interesante relato sobre sus diez meses de cautiverio entre

13 Geiger, O.F.M., Maynard: The franciscan conquest..., pág. 88. Deagan, Kathleen: Los misioneros y los matrimonios: el papel de las relaciones hispanoindias en la formación de una tradición hispano-floridana, en «La Influencia de España en la Florida, el Caribe y la Luisiana (1500-1800)». Madrid, 1983, pág. 275.

14 Todo ello fue una batalla entablada contra la poligamia indigena iniciada en la persona del cacique de Tolomato. Don Juan o Don Juanillo, irritado contra fray Pedro de Corpa, que realizaba allí su labor misional y que por su poligamia 10 apartó del mando. Gannon, Michael V.: The Cross..., pág. 40.

15 Ibídem, pägs. 99 y 100.

16 El libro de Omaechevarría, ya citado, está centrado en la figura de este misionero, la tarea que desarrolló en tierras floridanas y su muerte a manos de los indigenas. A.G.I., Santo Domingo, 224 y 229. 
los indígenas. ${ }^{17}$ También en el pueblo de Ays (en la parte sur, junto al cabo Cañaveral), mataron los naturales a un español, lengua de esta comarca, y a otros dos indígenas cristianos. ${ }^{18} \mathrm{El}$ gobernador Méndez de Canzo, junto con 100 soldados españoles y 200 indios aliados, fue el que puso fin a esta situación, a veces por la fuerza, sistema duramente criticado por los propios franciscanos, ${ }^{19}$ y otras mediante obsequios y agasajos. ${ }^{20}$

Para el estudio de este período contamos con la Relación Histórica del padre Oré, ${ }^{21}$ las octavas reales del padre Escobedo, en su poema La Florida, ${ }^{22}$ y la información oficial, a la que ya hemos hecho referencia y que se practicó en San Agustín en 1598 a raíz de los sucesos acaecidos. ${ }^{23}$

En la península se pretendió, lógicamente, conocer cómo se hallaba la provincia floridana tras los graves incidentes ocurridos. Se planteó la realización de una investigación, enviándose a San Agustín a Fernando de Valdés, hijo del gobernador de Cuba. Este, sorprendido, informó que había hallado a los franciscanos optimistas con respecto al futuro de su evangelización. ${ }^{24}$ Las directrices las tenían claramente establecidas y fijadas las bases para

17 Fernández del Pulgar, Pedro: Historia General de la Florida. Ms. 2999 de la Biblioteca Nacional de Madrid, fol. 210v. Gannon, Michael V.: The Cross.... págs. 41 y 42 . Geiger, O.F.M., Maynard: The franciscan conquest..., págs. 94-99 y $105-112$.

18 A.G.I. Santo Domingo. 235. San Juan del Puerto, 12 de octubre de 1599. De fray Francisco Pareja al Rey.

19 Ibídem. San Agustin, 8 de marzo de 1599. El padre Pareja se mostró siempre disconforme con los métodos extremistas y radicales empleados por el gobernador.

20 A.G.I., Santo Domingo, 224. El mismo gobernador, en un informe enviado al Rey desde San Agustín el 8 de agosto de 1598, informó haber conseguido el rescate de fray Francisco de Avila «dándoles e of reciéndoles muchas dádivas y regalos, porque de otra manera no fuera posible su rescate, que lo tenían muy metido tierra adentro en montes y pantanos».

21 Vid nota 2.

22 Vid nota 4. Aunque es extraño que sólo se mencione el martirio de cuatro religiosos, sin nombrar el de fray Blas Rodríguez.

23 A.G.I., Santo Domingo, 224. Para la realización de esta información fueron llamados a declarar varios indígenas. Gaspar de Salas actuó como intérprete y Juan Ximénez como notario.

24 Ibídem. En ese mismo año, se presentaron en la capital floridana 22 caciques que, además de jurar su obediencia al gobernador, en nombre del Rey español, solicitaron religiosos que los adoctrinasen. San Agustín, z3 de febrero de 1598 . Relación de los caciques que comparecieron. 
la gran tarea que se iniciaba y que alcanzarían tan importantes frutos en la centuria siguiente. Es ahora, cuando comanzaba la gran expansión misional en tierras floridanas.

\section{EL SIGLO XVII}

En 1604 el Rey Felipe III envió de nuevo a Florida frailes franciscanos de la provincia de los Angeles (en España) para proseguir la conversión del territorio; encontraron bastantes dificultades, a causa del período de apostasía en el que habían estado inmersos los indígenas tras la rebelión ocurrida. ${ }^{25}$ ¿Cómo reiniciaron su trabajo los religiosos franciscanos y establecieron las doctrinas en el territorio?

El receptor de envíos de las distintas expediciones ${ }^{26}$ fue siempre el convento de la Inmaculada Concepción, sito en la ciudad de San Agustín, como anteriormente hemos apuntado. Desde allí, el religioso era enviado al lugar en que era más necesario su ministerio. La misión estaba integrada generalmente por varios poblados, al más céntrico de los cuales, o más importante, se le designaba con el nombre de «cabecera», mientras que los restantes recibían la denominación de «estancias, aledaños o sujetos». La cabecera constituía el centro de acción del misionero. Se consideraba como su, residencia habitual y de ella partía, a intervalos más o menos frecuentes y por temporadas de duración diversa, a trabajar o inspeccionar las aldeas del distrito.

El ideal, que no siempre se cumplió, era que cada misión estuviese atendida por dos religiosos. En ese caso, mientras uno permanecía en la cabecera, el otro recorría los aledaños, turnándose sucesivamente. La ausencia del misionero era suplida en los

25 Omaechevarría, Ignacio: Sangre vizcaina..., pág. 148.

26 Las diferentes expediciones que se enviaron a Florida de 1600 a 1675 pueden ser consultadas en las Actas del III Congreso Internacional sobre los Franciscanos en el Nuevo Mundo (Siglo XVII). Madrid, 1991, págs. 813-884, donde Isabel Arenas Frutos, Carmen Cebrián González y Agustín Galán García, en sendos trabajos, analizaron las remisiones franciscanas a América a lo largo de este período. 
ancjos por indios especialmente instruidos (ladinos), a cuyo cargo corría la marcha externa de cada poblado. ${ }^{27}$

La tarea principal del doctrinero consistió en la enseñanza de la doctrina cristiana; para ello, y desde el primer momento de la evangelización, fue seguido un mismo esquema, llamado «método vertical»; el primero a quien se trataba de evangelizar era el cacique o señor principal de un paraje concreto. ${ }^{28}$ Una vez logrado esto, el resto de los habitantes, por sumisión o respeto, le secundaban.

Generalmente los más reacios al cambio de religión fueron lógicamente los ancianos, más arraigados a sus costumbres ancestrales. Esta afirmación la encontramos en la Relación del padre Pareja. ${ }^{29}$ Los indígenas llegaron incluso a pedir a los franciscanos que los fueran a enseñar ya que «los caciques de por acá, dijeron, que son más orobisi (sabios) nos lo dicen, y se han hecho cristianos. Nosotros también lo queremos ser, y guiarnos por lo que ellos dicen y hacen, enseñados por vosotros». ${ }^{30}$ Cuando ya una parte de la población, perteneciente a una región o pueblo concreto, estaba cristianizada, el misionero, con los escasos elementos con los que generalmente contaba, trataba de levantar una capilla donde celebrar los cultos. ${ }^{31}$

Aclaradas estas ideas generales en lo que a evangelización se refiere, pasamos a analizar la evolución progresiva que estas misiones experimentaron durante los años que venimos estudiando.

27 Borges Morán, Pedro: Los conquistadores espirituales de América. Seminario de Historia del pensamiento. Sevilla, 1961, pág. 82.

28 Morales Padrón. Francisco: Historia de América. Manual de Historia Universal. Tomo VI. Madrid, 1975, pág. 461.

29 Escrita por orden del padre fray Luis Jerónimo de Oré, que fue como visitador de la Provincia de Santa Elena de la Florida en 1614. Omaechevarría, Ignacio: Sangre vizcaína..., pág. 184.

30 Oré, Luis Jerónimo de: Relación histórica..., tomo I. pág. 111. Para los indigenas el cacique no era solamente el representante de la autoridad en el terreno político, sino el depositario de la verdad en el campo de lo religioso. La religión de los naturales se identiflcaba con la de sus jefes. Borges Morán. Pedro: Los conquistadores espirituales..., pág. 102.

$31 \quad \ldots .$. en todos los pueblos tienen sus iglesias y se precian de hacerlas unos mejores que otros». Oré, Luis Jerónimo de: Relación histórica..., tomo I, pág. 109. 
a) Primeros años de esta centuria

Durante estos primeros momentos del XVII, se tuvo la gran ventaja de contar con algunos franciscanos cuya labor resultó básica y fundamental, no sólo en lo que respecta a predicaciones y bautismos logrados entre los naturales, sino por la extrema dedicación e impulso conseguido entre la población aborigen en aspectos e instrucción cultural y material. Les enseñaron a leer, escribir, música, técnicas de cultivo, implantación de nuevos productos..., etc. Además, la enseñanza de la gramática española, llegó a ser, según los propios religiosos, un «medio eficacísimo para imprimir en aquellas tierras con letras, la disciplina y doctrina cristiana», ${ }^{32}$ lo que se tradujo en un rápido aumento del número de indios cristianos. Se comenzó a detectar una mayor interacción entre ambas culturas y como consecuencia de ello, una mejor comprensión mutua y respeto entre costumbres y formas de vida.

Estas afirmaciones se sustentan en una serie de informaciones, enviadas desde el propio territorio por los franciscanos mientras realizaban sus tareas evangelizadoras. Nos referimos en concreto a la que en 1602, envió desde San Agustín fray Francisco Pareja, explicando los logros obtenidos en sus siete años de enseñanza entre los naturales en la misión de San Juan del Puerto, donde contaba con un total de 500 personas cristianizadas. ${ }^{33}$ También

32 A.G.I., México, 302. San Agustín, 14 de octubre de 1630. Informe sobre la Florida de fray Francisco Alonso de Jesús. En esta faceta de la cngeñanza en Florida, destacó la figura de fray Francisco Pareja, natural de Auñón. de la provincia de Castilla. Llegó a aquellos territorios formando parte de la expedición que salío en $\mathbf{1 5 9 5}$ de Sanlúcar de Barrameda a las órdenes de fray Juan de Silva. E.jerció su ministerio en la misión de San Juan del Puerto. Se le definió como «varón de gran santidad y de increíble celo de la salvación de las almas». Imprimió las siguientes obras: Catecismo en lengua castellana y timucuana. México, 1617; Cathecismo y breve exposición de la doctrina cristiana. México, 1612; Confesionario en lengua castellana y timucuana, con algunos consejos para animar al penitente. Imp. Vda. de Diego López Dávalos. México, 1613; Arte y pronunciación en lengua timucuana y castellana. México, 1614; Cathecismo y examen para los que comulgan, en lengua castellana y timucuana. México, 1627. A.G.I., Contratación, 5.538. Geiger O.F.M., Maynard: Biographical dictionary..., pág. 85. Omaechevarría, Ignacio: Sangre vizcaína..., págs. 83 y 84 .

33 A.G.I., Santo Domingo, 235. San Agustín, 14 de septiembre de 1602. San Juan, como cabecera de misión, tenía de aledaños: La Vera Cruz (a media legua), 
la de fray Baltasar López, desde el pueblo e isla de San Pedro, donde había 792 indígenas cristianizados ${ }^{34}$ y Guale, donde según informó, ascendía el número a 1.200 .

Por los cálculos que se realizaron, en 1607 se contabilizó en 4.000 el número de los naturales bautizados ${ }^{35} \mathrm{y}$ por la crónica de fray Antonio Daza había en tierras floridanas 4 conventos y 13 vicarías; ${ }^{36}$ en tan sólo unos cuantos años (1617), la cifra de cristianos se duplicó. Esta era muy elevada ya que aún no había doctrinas establecidas en las provincias de Apalache, Tama, Santa Elena, ni en la costa de San Carlos (provincia floridana de Calus). ${ }^{37}$

El desarrollo misional hasta mediados de ese siglo destaca por el gran avance que se fue experimentando. La interesante y extensa información proporcionada por fray Alonso de Jesús en $1630,{ }^{38}$ nos aporta importantes datos sobre los indígenas floridanos, sus costumbres y formas de vida, al igual que sobre las misiones y el desarrollo de éstas, indicando que había ya por estas fechas en pie más de 600 iglesias repartidas en 32 doctrinas y atendidas por 27 religiosos, para a los pocos años (1634) ascender de nuevo a 35 franciscanos, atendiendo a 44 misiones y doctrinas. ${ }^{39}$ Este sería el proceso gencral hasta llegar a mediados de siglo, en el cual el avance evangelizador fue roto esporádicamente por alguna que otra revuelta indígena, ante el rechazo del trabajo impuesto

Ratobo (a dos y media), Molo (a cinco), Potaya (a una), Chinisca (a una $y$ media), San Mateo (a dos), San Pablo (a una y media), Hicachirico (a una) y Cavabay (a un cuarto de legua).

34 Ibídem. Pertenecía además a esta misión la isla de Napoyca (a una legua de San Pedro), con dos pueblos: Santo Domingo, con 180 cristianos y Santa María de Gena; también San Antonio con 30 y Chicafaye la Madalería (junto al anterior) con 40. Gannon, Michael V.: The Cross.... pág. 43.

35 Geiger O.F.M., Maynard: Biographical dictionary..., pág. 123.

36 Esta crónica data de 1611. Aspurz, O.F.M.. Lázaro: Magnitud del esfuerzo misionero de España. «Missionalia Hispánica», núm. 7. Madrid, 1946, págs. 130-146.

37 A.G.I. Santo Domingo, 235. San Agustín, 17 de enero de 1617. Informe cie varios religiosos (fray Francisco Pareja, fray Lorenzo Martínez, fray Pedro Ruiz, fray Alonso Pesquera, fray Juan de la Cruz, fray Bartolomé Romero), al Rey.

38 Vid nota 32.

39 Gannon, Michael V.: The Cross..., pág. 54. Montalbán, S.J., Francisco Javier: Manual de Historia de las misiones. Bilbao, 1952, pág. 423. 
por los españoles. La más importante de éstas tuvo lugar en 1647 , siendo reprimida y castigándose duramente a los promotores del suceso. ${ }^{40}$

Antes de continuar con el desarrollo misional merecería la pena destacar algunos aspectos y características que consideramos importantes, relacionados directamente con el estudio que venimos efectuando: El doctrinero no tenía fijado un tiempo concreto de estancia en la doctrina, éste sólo estaba establecido por las leyes de permanencia en Indias y era de 10 años completos, ${ }^{41}$ residiendo en el lugar que se le asignaba hasta que sus superiores le enviasen la orden de traslado a otro lugar. Para controlar el normal desenvolvimiento de estas misiones se realizaron en esta centuria diferentes «visitas» a las mismas, tanto eclesiásticas (realizadas por los obispos o sus delegados) como por visitadores de la propia Orden (las efectuadas por fray Luis Jerónimo de Oré). ${ }^{42}$ Con respecto a la congrua o estipendio que recibieron por su trabajo misional, éste fue estipulado entre el Rey y el Consejo de Indias, entregándose en un principio al provincial de la Orden en Florida para que se ocupase de su distribución. Esta cantidad era de 115 ducados (158 pesos) equivalente a una plaza de soldado del presidio. Como esta asignación, según los propios religiosos, resultase insuficiente debido al incremento progresivo de los precios, establecieron en sus respectivas doctrinas algunos aprovechamientos, sembrándoles los indígenas trigo, «una sabana para el padre y otra para la iglesia»; también les cultivaron tabaco y les criaron ganado de cerda, aves y otras legumbres, «que todo importa al año muy buena porción, porque estos géneros por mano de sus sindicos los envían a vender». ${ }^{43}$

40 Gannon, Michael V.: The Cross..., págs. 56 y 57.

41 Ley 16, título 12, libro I. Recopilación de Leyes de los Reynos cle las: Indias. Madrid, 1973, tomo I, pág. 53.

42 Arenas Frutos, Isabel: La Iglesia en la Florida española a través de las visitas eclesiásticas (Siglo XVII). «Actas del VIII Congreso de la Asociación de Historiadores Latinoamericanistas Europeos (A.H.I.L.A.)», tomo I. Szeged (Hungría), 1989, págs. 243-263.

43 A.G.I., Santo Domingo, 229. San Agustín, 18 de abril de 1692. Del gobernador Don Diego de Quiroga y Losada, al Rey.

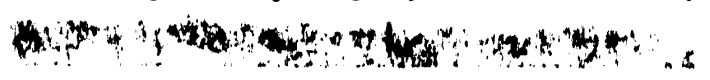


b) Estado de las misiones a mediados de siglo

En estas fechas se contaban cerca de 40 doctrinas, dispuestas en torno a la ciudad de San Agustín. "Estal distribución era la siguiente:

1. “La ciudad de San Agustín, donde estaba el Convento Capitular y de ordinario residía allí Guardián, Predicador y dos legos; ahí se trasladaban a curarse todos los religiosos enfermos de las doctrinas de aquella Provincia.

Por la costa del Norte

2. La doctrina del pueblo de Nombre de Dios, a un cuarto de legua de la capital.

3. Nuestra Señora de Guadalupe, a tres leguas.

4. San Juan del Puerto, es costa de mar, a 12 leguas.

5. San Pedro de Mocaho, a 20 leguas.

6. San Buena de Boadalquibi (San Buenaventura de Guadalquini), a 32 leguas (Jekil Island, Georgia).

7. Santo Domingo de Talege, a 4.0 leguas (cerca de Darién, Georgia))

8. San Joseph de Zápala, a 45 leguas (Sapelo Island, Georgia).

44 Chatelain, Verne E.: The defenses of Spanish Florida (1565-1763). Washington D.C., 1941, pág. 219. . Keegan, Gregory J. y Tormo Sanz, Leandro: Expe. riencia misionera en la Florida (S. XVI y XVII). Instituto \&Santo Toribio de Mogrovejo». (C.S.I.C.). Madrid, 1957, pág. 353. Aparece la misma relación de doctrinas y misiones que en la obra de Chatelain, solamente se añade la doctrina de Caoba, en la cordillera de Apalache, distante 150 leguas de la ciudad de San Agustín. Hann, John H.: Summary guide to Spanish Florida Missions and Visitas with churches in the Sixteenth and Seventeenth Centuries. «The Americas», vol. XLVI, núm. 4, april 1990. En este artículo se incluyen además los «anejos» o lugares visitados por los franciscanos, al igual que pequeñas ermitas o apeaderos. 
9. San Phelipe, a 54 leguas ientre Darién y Savannah, Georgial.

10. Santa Catalina de Gualé, a 50 leguas; era la principal de esta región (San Catherine Island, cerca de Port Royal, Carolina del Sur).

11. Chatuache, a 60 leguas (cerca de Charleston, Carolina del Sur).

12. Santiago de Ocone, isla, a 30 leguas.

Hacia el Oeste de San Agustin (zona timucuana)

13. Santa Cruz de Tarica, a 34 leguas.

14. San Agustín de Urica, a 60) leguas.

15. Santa María de los Angeles de Arapaja, a 70 leguas.

16. Santa Cruz de Xachipile, a 70 leguas.

17. San Ildefonso de Chamini, a otras 70 leguas.

18. San Francisco de Chuaquin, a 60 leguas.

19. San Pedro y San Pablo de Potuhiriba, a 60 leguas.

20. Santa Elena de Machaba, a 64 leguas.

21. San Miguel de Asile, a 75 leguas.

En la provincia de Apalache (cerca de la bahía del mismo nombre)

22. San Lorenzo de Apalache, a 75 leguas.

23. San Francisco de Apalache, a 77 leguas.

24. La Concepción de Apalache, a 77 leguas.

25. San Joseph de Apalache, a 84, leguas.

26. San Juan de Apalache, a 86 leguas.

27. San Pedro y San Pablo de Apalache, a 84 leguas.

28. San Cosme y San Damián, a 90 leguas.

29. San Luis de Apalache, a 88 leguas.

30. San Martín de Apalache, a 87 leguas. 
Al (Oeste de San Agustin (provincia de Timucua).

31. San Martín de Ayaocuto, a 31 leguas.

32. Santa Fe de Toloco, a 30 leguas.

33. San Francisco de Potano, a 23 leguas.

Al Sur de San Agustín

34. San Luis de Acuera, a 32 leguas.

35. Santa Lucía de Acuera, a 34 leguas.

30. San Antonio de Nacape, a 20 leguas.

37. San Salvador de Mayaca, a 36 leguas.

38. San Diego de Jaca, a 7 leguas».

El aparecer la parte sur de la península floridana, habitada por la familia Calusa, despoblada de doctrinas, se debe a que fue en esta región donde los jesuitas ejercieron su ministerio, que, como hemos apuntado al comienzo de nuestro trabajo, resultó un evidente fracaso, debido principalmente a la belicosidad de sus habitantes, refractarios a las predicaciones misionales.

Esta fue la cota máxima alcanzada por las misiones en el territorio ya que a partir de este momento su número fue decreciendo paulatinamente a causa de dos factores principales: muchos indios se aliaron con los ingleses de Carolina del Sur, abandonando sus pueblos; la población indígena disminuyó por las epidemias y enfermedades llevadas por los españoles. ${ }^{45}$

45 Arenas Frutos, Isabel: Fuentes para el estudio de la población indígena, en «Fuentes para la Historia Social de la Florida española (1600-1763)». Fundación España en U.S.A. Madrid, 1987, págs. 153-161. 


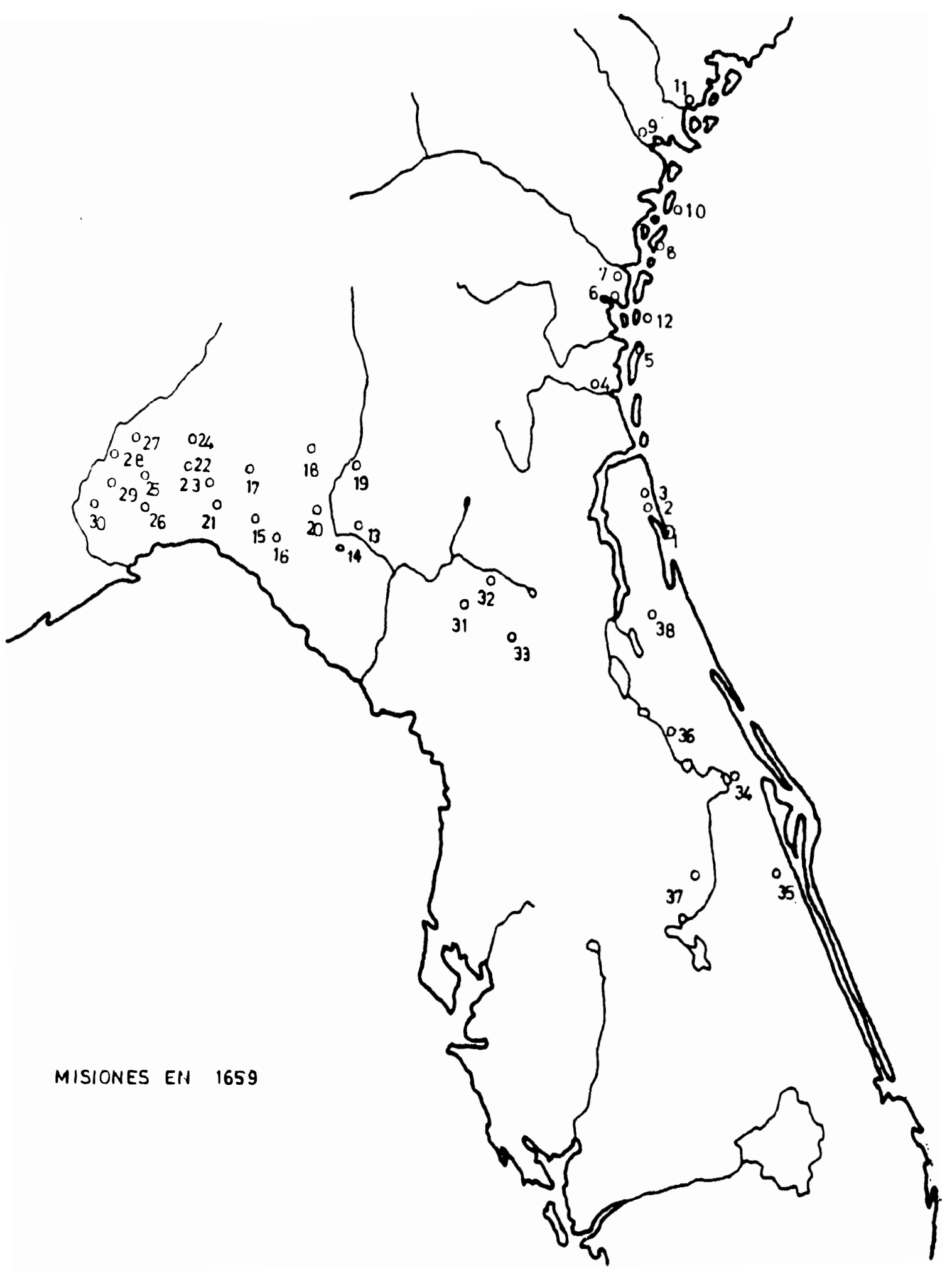




\section{c) Finales del XVII}

En 1680 había un total de 53 religiosos empleados en las misiones; de ellos, tres ministros, se encontraban en el convento de San Agustín para administrar a los naturales en los tres idiomas (guale, timucua y apalache). Los restantes franciscanos se hallaban repartidos, a su vez, entre las provincias de Guale y Mocama, Timucua y Apalache. ${ }^{46}$

Es además por estas fechas (1689) cuando se realizó el censo más preciso de las misiones floridanas, al enviar el obispo de $\mathrm{Cuba}^{47}$ a la Corona una lista de las diferentes doctrinas, con el número de familias nativas pertenecientes a cada una de ellas. ${ }^{48}$ Florida se hallaba dividida en cuatro provincias:

-Guale con 6 doctrinas y un total de 185 familias. ${ }^{49}$

- Tomucu (Timucua) con 13 doctrinas y 591 familias.

-Apalache, la más próspera de ellas, también con 13 doctrinas y 1.920 familias.

- La «provincia nueva» localizada en el sur, con tan sólo 2 doctrinas y 100 familias.

En total pues, 2.796 familias. Estimándose que cada una de ellas podía estar compuesta por 5 miembros, se contaban 13.980 personas. Además el censo de la ciudad de San Agustín

46 «Relación de los religiosos existentes en las conversiones de la Florida y pueblos donde están las doctrinas». Notas de Woodbury Lowery; en Chatelain. Verne E.: The defenses..., pág. 123.

47 Florida dependió en el aspecto eclesiástico de Cuba durante los siglos XVI y XVII; hasta comienzos del XVIII no se erigió como obispado independienle, aún persistiendo ciertá subordinación.

48 Arnade, Charles W.: The siege..., pág. 9. Hilton, Sylvia-Lyn: Ocupación española de Florida: Alounas repercusiones en la oroanización socio-politica indigena, siglos XVI y XVII. «Revista de Indias», vol. XLII, enero-junio 198ð, págs. 41-70.

49 A.G.I., Santo Domingo, 2.584. Contamos además con una lista detallada de los pueblos pertenecientes a esta provincia, la distancia existente entre ellos y el número de personas que los habitaban, entre los que se contaban también infieles, así como los nombres de los neligiosos que los asistían. Tupiqui, 4 de junio de 1681 . 
era de 500 familias ó 1.444 personas, incluyendo blancos, indios y negros.

De estas mismas fechas poseemos también una interesante relación de los ornamentos, prendas y alhajas que, para el culto divino, tenían las iglesias de estas conversiones, ${ }^{50}$ consistente en:

- 992 campanas para tocar misa.

- 242 amitos.

- 196 manteles de altar.

- 183 imágenes de Nuestra Señora, niños Jesús y diferentes santos.

- 71 misales, algunos nuevos y otros usados.

- 47 cálices con sus patenas de plata.

- 20 linternas y faroles.

Los años finales de esta centuria no serán ya más que un lento declinar del sistema misional franciscano. Sucesivos pueblos indígenas se aliaron a los ingleses en su lucha contra el gobierno español por el dominio de aquella provincia. Estos ataques resultaron auténticas «razzias» que fueron minando cada vez más los debilitados cimientos del mundo hispano; la frontera establecida entre ambas naciones fue avanzando inexorablemente hacia el sur, situación tensa y difícil con la que se iniciaba un nuevo período.

\section{El SIGLO XVIII}

Esta nueva centuria comenzó en un ambiente de presión continua: españoles, indígenas e ingleses se mostraban desconfiados y a la expectativa de acciones ofensivas y defensivas por parte de alguno de ellos. El gobierno español llegó incluso a dictar una

50 A.G.I.. Santo Domingo, 835. Convento de la Limpia Concepción de San Agustin de la Florida, 16 de junio de 1681. 
serie de normas ${ }^{51}$ prohibiendo, en una de ellas, la posesión por parte de los naturales de armas de fuego, aunque les estaba ordenado mantener sus armas indígenas, caso de tener que defender su aldea de alguna posible agresión por parte de los vecinos del norte.

\section{a) Asalto a la ciudad de San Agustin}

El 10 de noviembre de 1702 se produjo, por parte inglesa y aliados indígenas, un devastador ataque contra la capital floridana. Este se produjo, no sólo por mar (con unas 14 ó 15 naves), sino también por tierra, poniendo sitio a la ciudad durante 51 días, teniendo que refugiarse sus habitantes al amparo del castillo. ${ }^{52}$ Ya el primer día que atacaron la ciudad, quemaron la amplia biblioteca (unos 600 volúmenes) del convento franciscano. ${ }^{53}$

Al recibir los españoles ayuda de La Habana, los atacantes huyeron prendiendo fuego además a la iglesia parroquial, al convento franciscano, ${ }^{54}$ hospital y unas veinte casas. En su huida quemaron siete doctrinas más (Nombre de Dios, Tupiqui, San Felipe, Santa María, San Juan del Puerto, Salomototo e Itolomaso), de las que no quedaron señal alguna, al ser sus fábricas de madera y cercadas de lo mismo; ${ }^{55}$ arrasaron los campos, frutales, y mataron el ganado mayor. ${ }^{56}$ Se llevaron además a tres religiosos prisioneros (fray Domingo Posso, fray Domingo Santos y fray Manuel de Urira), ${ }^{57}$ los cuales estuvieron cautivos durante tres años, su-

51 TePaske, John J.: The Governorship of Spanish Florida (17001763). Durham, North Carolina, 1964, págs. 194-196.

52 The dramatic Story of Spain's great 17th century Fortress in Saint Augustinte. Jacksonville, Florida, 1966, pág. 11.

53 Gannon, Michael V.: The Cross..., pág. 74.

54 A.G.I., Santo Domingo, 854. Este convento medía en total, 56 varas de largo, 6 de ancho e igual de altura. Las tasas para su posterior reedificación, incluida la madera, se fljaron en 10.000 pesos. San Agustín, 26 de octubre de 1724 .

55 A.G.I., Santo Domingo, 841 y 864. San Agustín, Informes de 1703.

56 Ibídem.

57 A.G.I., Santo Domingo, 864. San Agustín, 7 de mayo de 1707. Informe de varios religiosos. A.G.I., México, 2.730. Según real cédula promulgada en Barcelona a 15 de marzo de 1702, en Florida había, al producirse el ataque inglés, un total de 4.3 religiosos asistiendo sus misiones. 
friendo grandes penalidades, hasta que por fin pudieron ser rescatados.

Conocemos muchos pormenores de la deplorable situación en que quedó la capital floridana, al haberse enviado a fray Martín de Alacano a España para realizar diversas peticiones de ayuda, ${ }^{58}$ aunque desde aquella provincia no dejaron tampoco de realizarse. ${ }^{59}$

En 1704, los ingleses atacaron también la provincia de Apalache, matando a dos misioneros (fray Juan de Parga, de la provincia de Santiago, que realizaba su labor misional en la misión de Pataly. Era un gran predicador, habiendo realizado dicho oficio en la iglesia parroquial de San Agustín durante una cuaresma. El otro religioso fue fray Manuel de Mendoza. Ambos conocían muy bien la lengua de los indígenas), ${ }^{60}$ y 40 indios, además de hacer prisionero a otro franciscano. ${ }^{61}$

El número de doctrinas destruidas o abandonadas por sus habitantes alcanzó casi la treintena, ${ }^{62}$ achacándose el hecho a la falta de armas adecuadas por parte de los indios que se hallaban bajo el amparo de los españoles, para resistir los ataques ingleses. ${ }^{63}$ Además, los indígenas que no se habían reducido a pueblos, vagaban por los montes huyendo de los enemigos y algunos religiosos que los siguieron sufrieron muchas penalidades. ${ }^{64}$ Estos dos grandes ataques ingleses, marcaron el comienzo de la decadencia de las misiones franciscanas en Apalache, Timucua y Guale, tras los 130 años de labor ininterrumpida de la Orden en aquellos territorios. ${ }^{65}$

58 A.G.I., Santo Domingo, 864. La Habana, 30 de enero de 1703. Memorias de las diligencias que este religioso ha de realizar en la corte de Madrid.

59 A.G.I., Santo Domingo, 836. Madrid, 9 de julio de 1703. Acuerdo del Consejo para que se entreguen las limosnas pedidas desde la Florida, para la reedificación de las distintas iglesias quemadas por los ingleses.

60 A.G.I., Santo Domingo, 864. San Agustin, 6 y 9 de junio de 1705. Informes de diversos testigos.

61 Ibidem, fray Angel de Miranda, de la misión de Ayubaly.

62 A.G.I., Santo Domingo, 841. San Agustín, 13 de agosto de 1706. Informe sobre la extinción de 29 doctrinas de indios cristianos.

63 Deagan, Kathleen: «Los misioneros y los matrimonioj...». pág. 276.

64 A.G.I., Santo Domingo, 864. San Agustín, 7 de mayo de 1707. Informe cnitiado pcr varios franciscanos.

65 A.G.I., Santo Domingo, 840 y 843 . TePaske, John J.: The Gotkernorship..., págs. 196 y 197. 
b) Intentos de reorganización misional tras las agresiones británicas

Los comienzos, pues, de esta centuria en cuanto a misiones se refiere, son bastante negativos. Nunca, durante este amplio período que venimos analizando, fue tan decadente la influencia española sobre los indígenas. ${ }^{6}$ Los franciscanos, en un último intento evangelizador, trataron de rehacer en lo posible la situación misional con los pocos pueblos que aún permanecieron fieles a la Corona española, reuniéndolos en torno a la ciudad de San Agustín, al abrigo del castillo y buscando su protección frente a posibles nuevos ataques, ayudándolos en sus necesidades físicas y espirituales.

La situación se mantuvo relativamente estable por algunos años en la provincia, incluso, en 1715, pareció que los españoles hubiesen podido recuperar sus alianzas indígenas puesto que cuatro caciques, representando 161 aldeas de Apalache, fueron a San Agustín pidiendo ayuda y protección al gobernador. Estas tribus, alia. das de los ingleses durante la guerra, se habían rebelado contra éstos al término de la contienda (1713) al habérseles exigido, por la fuerza, el pago de municiones y provisiones que se les había proporcionado. El gobernador español pensó, que una alianza con estos pueblos indígenas podía abrir un nuevo camino para el renacimiento de la misión franciscana. Consiguió un incremento en la cantidad asignada para ayuda de los naturales (de 2.063 pesos a 6.000), ${ }^{67}$ contando también con el apoyo del procurador general franciscano de la provincia de Santa Elena. ${ }^{68}$ Envió para ello, en 1716, al noroeste, al teniente Diego Peña, ${ }^{69}$ a ratificar esta

66 A.G.I., Santo Domingo, 841 y 843. TePaske, John J.: The Governorship..., pág. 197.

67 A.G.I., Santo Domingo, 843. San Agustín, 25 de enero de 1716. Informe del governador al Rey. TePaske, John J.: The Governorhip..., pág. 198.

68 A.G.I., Santo Domingo, 864. San Agustín, 13 de julio de 1716. Fray Antonio de Florencia al Rey.

69 Este hizo un interesante diario de su viaje. TePaske, John J.: The Governorship.... págs. 200 y 201. Santo Domingo, 842 y 843. San Agustín, 13 de diciembre de 1717. 
alianza con los apalaches. Sin embargo, este acuerdo entre espanoles e indígenas, tras sucesivos intentos, y, a pesar de contar con el decidido auxilio misional de los franciscanos, ${ }^{70}$ no llegó a realizarse, debido principalmente a la falta de recursos económicos por parte española. ${ }^{71}$

Los religiosos hubieron de conformarse con continuar su labor con los pocos indígenas que aún eran aliados de la Corona, ${ }^{72}$ proveyéndoles de comida y suministros de los almacenes de San Agustín. Por real cédula de 26 de mayo de 1725 se ordenó que fuesen visitados estos pueblos de indios, tanto los de Apalache -con un total de 16 doctrinas y 1.011 personas - , ${ }^{73}$ como los cercanos a San Agustín -11 pueblos, integrados por yamasees, timucuanos y guales - ${ }^{74}$ Estos, próximos al presidio, se redujeron enormemente, atacados, tanto por epidemias, ${ }^{75}$ situación que alarmó enormemente a las autoridades españolas que solicitaban desde la península continuos informes, ${ }^{76}$ como por los acosos de repetidos ataques enemigos, ${ }^{77}$ como el que se efectuó en 1728 , en el que se llevaron muchos prisioneros, dejando despobladas algunas doctrinas, puesto que los pocos indios que quedaron se fueron a vivir a la ciudad.

Esta situación misional afectó seriamente a los religiosos franciscanos; su labor evangelizadora, a la vista de resultados tan negativos, se relegó bastante, denotándose gran apatía en este terreno. Tanto el Capítulo, como la moral conventual, llegó a ser más

70 A.G.I., Santo Domingo, 864, 837 y 84¿, respectivamente. Madrid, 10 de Diciembre de 1717, 4 de Febrero de 1718 y San Agustín, 8 de Marzo de 1722.

71 TePaske, John J.: The Governorship.... págs. 205 y 206.

72 A.G.I., Santo Domingo, 866 y 842, respectivamente. Testimonios del bautismo de 299 indios adultos y 105 párvulos. San Agustín, 25 de Febrero de 1723 y 7 de Noviembre de 1724.

73 A.G.I., Santo Domingo, 844 y 866. San Agustín, 1 de Diciembre de 1726. Informes del gobernador y escribano público sobre la visita realizada.

74 A.G.I., Santo Domingo, 866. Convento de San Francisco de la Habana, 13 de Agosto de 1728. Copia de un informe sobre el estado de las doctrinas cercanas a San Agustín.

75 A.G.I., Santo Domingo, 844 y 866. San Agustín, 10 de Septiembre de 1727. Informe del gobernador sobre la muerte por epidemias de 166 indios cristianos, acogidos al presidio, tras realizar la visita ordenada en $17<5$.

76 A.G.I., Santo Domingo, 2.593 y 2.604.

77 Vid nota 73. 
importante para ellos que su trabajo entre los naturales. ${ }^{78}$ En 1727 , 17 frailes franciscanos regresaron a Cuba, en contra de la política seguida por el gobernador. ${ }^{79}$

En Madrid, sin embargo, el nuevo comisario general, fray Domingo Losada, defendió la actitud de los misioneros, ya que afirmó que los que se marcharon, hablan cumplido su estancia en las cercanías de San Agustín, 9 vivían en el convento y 2 permanecían en Pensacola y Apalache. ${ }^{80}$

\section{c) Las desavenencias entre frailes criollos y peninsulares}

En 1735, surgió un grave conflicto entre ambas parcialidades religiosas y que incidió de manera notoria en el sistema misional, al sufrir éste una gran regresión y achacársele en parte a esta problemática, la falta de evangelización y trabajo misionero que a partir de entonces se detectó. Es en esta fecha cuando se delimitan claramente ambos grupos: por un lado, los criollos amparados por el gobernador de la colonia, por otro, el Rey y los frailes peninsulares.

El monarca español, llegó a ver a los criollos como conspiradores, intentando mantener la supremacía. ${ }^{81}$ Es por ello que, en Florida, como en otros territorios del Nuevo Mundo, se pretendió que estuvieran siempre bajo las órdenes de sus superiores peninsulares. Los criollos, tan sólo en ocasiones, llegaron a ser virreyes, arzobispos o gobernadores.

En Florida, en estos años, los criollos llegaron a controlar la situación de la Orden franciscana, haciéndoles, según afirmaron los religiosos peninsulares, ${ }^{82}$ deliberadamente imposible la vida,

78 TePaske, John J.: The Governorship..., pág. 181.

79 A.G.I., Santo Domingo, 866. San Agustín, 18 de Septiembre de 1727. El gobernador Benavides al Rey.

80 TePaske, John J.: The Governorship..., pág. 182.

81 Ibídem, pág. 183.

82 A.G.I., Santo Domingo, 864. San Agustín, 6 de Marzo de 1735. Amplio informe de los religiosos peninsulares que residen en estas conversiones. 
al enviarlos a las aldeas más hostiles y miserables, siendo casi forzados a abandonar la colonia. Entre los años 1731 y 1732, habían llegado a San Agustín 9 franciscanos. ${ }^{83}$ Aparte de haberlos enviado a los pueblos más pobres, se les estuvo cambiando continuamente de lugar y por ello no tenían ocasión de aprender ninguna de las lenguas indígenas para evangelizar a los naturales. Como ejemplo de lo comentado, podríamos citar el caso de fray Pedro de León y Cordero, que desde el año 1732, en que llegó, hasta 1735, residió en Porotalaca, Jororo, fuerte de Apalache, Costa, Rosas, Tolomato y de nuevo Costa (donde permanecía en este año). El destino de los otros 8 misioneros fue prácticamente el mismo. ${ }^{84}$

El gobernador y frailes criollos acusaron a los misioneros peninsulares, de malos tratamientos con los indígenas; a los primeros se sumó además el obispo auxiliar fray Francisco de San Buenaventura, ${ }^{85}$ llegado por estas fechas, y que en un primer momento, estableció buenas relaciones con el gobernador. La situación se mantuvo muy tensa durante unos años; ambas facciones, criollos y peninsulares, trataron de conseguir las máximas prerrogativas y ventajas, no resolviéndose el asunto hasta el traslado del gobernador en $1737 .{ }^{86}$

\section{d) Nuevas tentativas para un resurgimiento del campo misional}

En el año posterior (1738), al acabar la grave tensión surgida dentro del clero regular, parece que se intentó de nuevo un renacer en el aspecto doctrinal. Ello nos lo confirman, los múltiples informes que se enviaron a la península, dando la sensación de ser un firme propósito de recuperación de los años anteriores. Los

83 Ibídem. San Agustín, 25 de Febrero de 1735. Informe de Don Francisco Menéndez Márquez, contador de la Real Hacienda y Cajas Reales, al Rey.

84 Ibídem.

85 Arenas Frutos, Isabel: De San Pablo de la Breña a San Agustin de la Florida: San Francisco de San Buenaventura, obispo de Tricali. «Actas de las IV Jornadas de Andalucía y América», tomo II. Sevilla, 1985, págs. 313-322.

86 Ibídem. 
religiosos que habitaban el convento de San Agustín en esta fecha eran 12, teniendo a su cargo un total de 24 naturales que vivían en la ciudad. De las misiones se ocupaban a su vez 12 y los pueblos donde ejercían su ministerio eran: ${ }^{87}$

-Nombre de Dios Macaris.

- San Antonio de la Costa.

-Nuestra Señora de Guadalupe de Tolomato.

- San Juan del Puerto de Palica.

- Nuestra Señora de la Asunción de Palica.

-Nuestra Señora de la Concepción de Porotalaca.

- Nuestra Señora del Rosario de la Punta.

-Nombre de Dios Chiquito.

- San Nicolás de Casapullas.

-Tamasle, en Apalache.

Entre todos, religiosos e indígenas, sumaban unas 400 personas.

Aún en 1743, por los nuevos ataques ingleses, las aldeas se redujeron todavía más, quedando tan sólo 4 (Tolomato, Palica, Porotalaca y Punta), pretendiendo los españoles nuevas alianzas con las tribus indígenas, pero sin resultados satisfactorios. ${ }^{88}$

En 1753, el virrey de Nueva España propuso ${ }^{89}$ que 11 frailes podrían cubrir las necesidades de la colonia: un superior y cinco franciscanos en el convento de San Agustín, con tres hermanos legos para la enseñanza de los niños de la ciudad y dos misioneros más para trabajar entre los indígenas, pudiéndose centralizar todos estos proyectos en dos lugares, Tolomato y Punta, aumentándose

87 A.G.I., Santo Domingo, 864, 866 y 867. 1738. Nómina de las doctrinas pertenecientes al presidio de San Agustín, doctrineros y personas que plertenecen a cada una de ellas.

88 TePaske, John J.: The Governorship..., págs. 215-225.

89 1753. Reglamento para la guarnición de la Habana, castillos y fuerkes cie su jurisdicción: Santiago de Cuba, San Agustin de la Florida y su anjexo, San Marcos de Apalache. Ibídem, pág. 191. 
incluso el estipendio de los religiosos para así incentivarlos en su labor. En el siglo anterior, como comentamos, este sueldo era de 115 ducados (158 pesos) anuales. En 1706 se elevó a 200 pesos y ahora se aumentó hasta $300 .^{90}$

\section{e) Ultimos años de este periodo}

En 1759, la reducción en el número de indígenas, fieles a los españoles, era aun más evidente. En la capital y alrededores, incluyendo los pueblos de Tolomato y Moze, ${ }^{91}$ no llegaban ni a los 80 ; cerca de San Marcos de Apalache, tan sólo quedaba una aldea, Tamasle, con no más de 25 habitantes. ${ }^{92}$ En todo el territorio apenas permanecían 10 religiosos. ${ }^{93}$

Aunque en 1763, se intentaron establecer nuevas alianzas con los indígenas, éstas evidenciaron ya su manifiesto retraso, pues ese mismo año los españoles hubieron de evacuar Florida para dejarla a los ingleses. ${ }^{94}$

\section{Is abel Arenas Frutos}

90 A.G.I., Santo Domingo, 849. México, 3 de Abril de 1759. El virrey de la Nueva España al Rey. Por Real Cédula de 17 de Mayo de 1757 se incrementó el salario de los misioneros de Florida.

91 A.G.I., Santo Domingo, 844 y 846. El 16 de Febrero de 1739, el gobernador informó haber fundado este pueblo, llamándole Gracia Real de Santa Teresa de Moze, formado por los negros fugitivos de las colonias inglesas, asignándole un capellán. Sin embargo, en 1758, se nombró como misionero a fray Ginés Sánchez, atendiéndolo desde entonces los franciscanos.

92 A.G.I., Santo Domingo, 2.584. Santiago de Cuba, 9 de Octubre de 1759. Informe del obispo. A.G.I., Santo Domingo, 2.604. San Agustín, 14 de Abril de 1759. El gobernador al Rey. Inventario de los pueblos de indios. TePaske, John J.: The Governorship..., pág. 224.

93 A.G.I., Santo Domingo, 2.584. San Agustín, 22 de Abril de 1759. De fray Joseph Solana al Rey.

94 TePaske, John J.: The Governorship..., pág. 225. 